\title{
TECNOLOGIAS GLOBAIS NA PRODUÇÃO DE VACINAS CONTRA O COVID-19
}

\section{GLOBAL TECHNOLOGIES IN THE PRODUCTION OF VACCINES AGAINST COVID-19}

\author{
Sando Bichara Mendonça'; Thaís Pacheco Soares²; César Ronald³; Rogério da Silva Burla4; Cícero de Souza \\ Amorim $^{5}$ \\ 1. Mestre em Educação Ciências e Saúde - UFRJ / NUTES- Brasil; Médico Oncologista Clínico; Professor da \\ Faculdade de Medicina de Campos. \\ 2. Pós doutora em Biociências e Biotecnologia - UENF- Brasil; Doutora em Biociências e Biotecnologia com \\ ênfase em Bioquímica e Imunologia - UENF / LQFPP com Sanduíche na Universidade de Medica de Vienna - \\ Áustria; Mestre em Biociências e Biotecnologia UENF/LQFPP; Especialista em Comunicação Educacional; \\ Bióloga; Acadêmica de Medicina - UniRedentor. \\ ${ }^{3}$. Doutor em Produção Vegetal - UENF-Brasil; Mestre em Gestão Ambiental - Universidade Estácio de Sá- Brasil; \\ Médico, Professor titular da Faculdade de Medicina de Campos. \\ 4. Mestre em engenharia ambiental- IFF-Brasil; Engenheiro Agrônomo /UENF; Acadêmico da Faculdade de \\ Medicina de Campos. \\ 5. Acadêmico da Faculdade de Medicina de Campos. \\ Instituição de vínculo: Faculdade de Medicina de Campos \\ Autor responsável para correspondência: Sandro.bichara@gmail.com
}

\section{RESUMO}

Diante do cenário pandêmico da COVID-19, o esforço na produção de uma vacina contra o vírus tornou-se prioritário em todo mundo. Isso em razão da doença ser responsável, por milhares de mortes, além dos impactos econômicos mundiais decorrentes e sem precedentes nos últimos cem anos. $O$ objetivo desta revisão de literatura é promover uma discussão a respeito do contexto global e das diferentes plataformas de tecnologias aplicadas no desenvolvimento de imunização contra o SARS-CoV- 2 . Nossas informações são baseadas em bancos de dados de programas de desenvolvimento de vacinas relatados através da OMS, além dos trabalhos científicos disponíveis na literatura direcionados aos ensaios promissores. As pesquisas disponíveis na literatura visam induzir resposta imunológica com produção de anticorpos contra a proteína spike (S) viral, impedindo a adesão desta à enzima conversora de angiotensina (ECA2) e consequentemente, a interiorização do vírus na célula. Até esse momento, 150 candidatas foram registradas na OMS, em diferentes estágios. Muitas dessas plataformas são inovadoras ao mercado farmacêutico de vacinas licenciadas. Por outro lado, contamos com distintos paradigmas tecnológicos sendo colocados em pauta. Um exemplo a ser destacado é a tecnologia utilizada na vacina mRNA-1273, que codifica uma forma da proteína $S$ e demonstrou alta eficácia humana na produção de anticorpos. Os resultados clínicos têm alimentado grande esperança quanto ao controle da infecção, entretanto, nesse momento é necessário existir uma forte política cultural específica, que contemple e norteie todas as diretrizes éticas relacionadas com esse processo.

Palavras-chave - COVID-19; Vacinas; Tecnologias; Imunogenicidade.

\section{ABSTRACT}

In view of the pandemic scenario of COVID-19, the effort in producing a vaccine against the virus has become a priority worldwide. This is because the disease is responsible, for thousands of deaths, in addition to the global economic impacts arising and unprecedented in the last hundred years. The purpose of this literature review is to promote a discussion regarding the global context and the different technology platforms applied in the development of immunization against the SARS-CoV-2. Our information is based on a database of vaccine development programs reported through WHO, in addition to the scientific papers available in the literature aimed at promising trials. The research available in the literature seeks to induce an immune response with the production of antibodies against the viral spike $(\mathrm{S})$ protein, preventing its adhesion to the angiotensin-converting enzyme (ACE2) and, consequently, the virus's internalization in the cell. Up to this moment, 150 candidates have been registered with WHO at different stages. Many of these platforms are innovative to the licensed vaccine pharmaceutical market. On the other hand, there are different technological paradigms being placed on the agenda. An example to be highlighted is the technology used in the mRNA - 1273 vaccine, which encodes a form of protein $S$ and has demonstrated high human effectiveness in the production of antibodies in human bodies. The clinical results have fueled great hope regarding the control of the infection. However, at this moment it is necessary to have a strong specific cultural policy, which contemplates and guides all the ethical guidelines related to this process.

Keywords - COVID-19; Vaccines; Technologies; Immunogenicity. 


\section{INTRODUÇÃO}

Em dezembro de 2019, na cidade de Wuhan China foi identificada uma doença infecciosa, mais especificamente uma pneumonia por um novo vírus: Coronavírus 2019 (COVID-19). Em 11 de março de 2020 foi declarada pela Organização Mundial da Saúde (OMS) a pandemia por uma doença infecciosa definida como "Doença por Coronavírus 2019 (COVID-19)". O vírus foi, no entanto, descoberto e identificado pela primeira vez em um grupo de pacientes com pneumonia em Wuhan na China, em Dezembro de 2019 (CALLAWAY et al., 2020; ZHU et al., 2020).

Comorbidades tais como: doenças cardiorrespiratórias, diabetes mellitus e imunodeficiências, bem como idade avançada e gestante, foram consideradas como fatores e aspectos para curso grave, hospitalização e morte. Sendo o COVID-19 uma nova cepa viral, nenhum antiviral específico ou vacinas ainda estão disponíveis. Acredita-se que não haja imunidade préexistente na população (KLIMEK et al., 2020).

As infecções por COVID-19 podem ser clinicamente assintomáticas, causar doença leve com ou sem envolvimento pulmonar, ou levar as formas mais graves de pneumonia e falência de múltiplos órgãos. Os sintomas frequentes de infecções por COVID-19 são febre, tosse, falta de ar, e dificuldades respiratórias, bem como disfunção de paladar e olfato. Outros sinais de infecção viral das vias aéreas se apresentam com sintomas nasais e dor de garganta. Em casos mais graves, a infecção por COVID-19 pode levar a pneumonia, síndrome respiratória aguda grave, insuficiência renal, e morte, desencadeando grandes impactos humanitários e econômicos (KLIMEK et al., 2020). Na maioria dos casos, as pessoas são infectadas pelo COVID-19 através da inalação de aerossóis provenientes de espirros ou tosse, contato com superfícies contaminadas ou tratamento dentário. Considerando os fatores acima descritos, infecções por COVID-19 podem ser clinicamente assintomáticas, pouco sintomáticas ou evoluir com doença grave, com real potencial letal. Inicialmente cefaleias, febre, espirros, tosse seca, dor de garganta, mialgias e artralgias são as manifestações clínicas associadas à infecção pelo COVID-19. Hoje já se conhece muitas outras possíveis manifestações clínicas fortemente sugestivas da infecção pelo COVID-19: neurológicas, cardíacas, gastrintestinais, renais, dermatológicas e hematológicas. A cada dia outras vêm sendo descobertas.
O COVID-19 pode ser isolado através de coleta de Swabs nasofaríngeos ou amostras sanguíneas, opções escolhidas considerando o tempo de início das manifestações clínicas, seguidos de estudos específicos isolados in vitro em culturas de células (KLIMEK et al., 2020).

A pandemia global do COVID-19 está impulsionando o desenvolvimento de plataformas de tecnologias para produção de vacinas através de novos paradigmas científicos tecnológicos. A fim de oferecer ao mundo uma forma real e sustentável de prevenção da infecção e contingência da pandemia. A primeira vacina candidata entrou em testes clínicos humanos com rapidez sem precedentes em 16 de março de 2020 (SOCIEDADE BRASILEIRA DE IMUNOLOGIA, 2020).

\section{OBJETIVOS}

Este estudo tem como objetivo investigar, promover reflexões e discussões sobre as tecnologias globalmente desenvolvidas para produção de vacinas contra o COVID-19, além dos ensaios clínicos, a imunogenicidade e as manifestações clínicas de relevância relacionadas à infecção pelo Coronavírus.

\section{MÉTODOS}

O método para coleta de dados foi uma revisão e análise sistematizada de informações e dados disponíveis na literatura científica, relacionados com a produção global das tecnologias para a produção de vacinas contra o COVID-19, entre Março e Agosto de 2020.

\section{CARACTERÍSTICAS DO CORONAVIIRUS}

Os Coronavírus são zoonóticos, ou seja, são transmitidos entre animais e humanos. A atual infecção, a pandemia pelo COVID-19, é causada por uma nova cepa de Coronavírus humano, que foi nomeado pelo Comitê Internacional na Taxonomia de Vírus (ICTV) de SARS-CoV-2 (síndrome respiratória aguda grave-Coronavírus 2). SARS-CoV-2 é um Betacoronavirus do subgênero Sarbecovirus e da subfamília Orthocoronavirinae. Identificado como o sétimo membro da família Coronaviridae.

Análise filogenética revelou ser o SARS-CoV-2 um novo beta-CoV distinto do SARS-CoV e MERS-CoV. O qual é capaz de causar infecções humanas mais graves e potencialmente letais. Sugerindo com muito boa precisão muito maior virulência do SARS-CoV-2. Logo, particularmente muito mais preocupante para a saúde humana (ZHU et al., 2020).

Sabe-se que todos os vírus são 
potencialmente mutantes na medida em que avançam infectando novos seres vivos. OSARS-CoV-2 não é exceção. Este aspecto tem significativo impacto direto na produção de vacinas capazes de combater a infecção humana pelo COVID-19 (CORBETT, et al., 2020). Cientistas epidemiologistas de todo o mundo estudam estas mutações moleculares. Tanto para mapeamento da dispersão e prevalência global de determinada cepa viral, quanto para identificar possíveis mudanças no perfil molecular de constituição viral que Ihes permitam produzir anticorpos específicos contra antígenos virais. A primeira mutação do COVID-19 teria surgido na Itália, e identificada em Fevereiro de 2020. E vem sendo identificada, desde então, em todas as cepas estudadas nas diferentes regiões globais (ZHOU et al., 2020).

A sequência genética do SARS-CoV-2 foi publicada em 11 de janeiro de 2020, subsidiando informações científicas necessárias ao início de estudos que visem o desenvolvimento de plataformas tecnológicas para produção de vacinas contra a infecção pelo COVID-19. A estrutura viral do Coronavírus é composta por capsídeo membranoso lipídico, diferenciando-se dos Coronavírus relacionado à síndrome respiratória oriental (MERSCoV), responsável pela síndrome respiratória aguda grave (SARS-CoV), e do Coronavírus responsáveis pelo resfriado comum (229E, OC43, NL63 e HKU1) (RABAAN et al., 2020).

O Gráfico 01 apresenta os dados comparativos das taxas de mortalidade entre MERSCoV, SARS-CoV e SARS-CoV-2. A partir dos dados apresentados é possível observar que o SARS-CoV-2, apresenta o menor índice de mortalidade. Por outro lado, entre eles, o MERS-CoV é o que detém a maior taxa de mortalidade, (RABAAN et al., 2020).

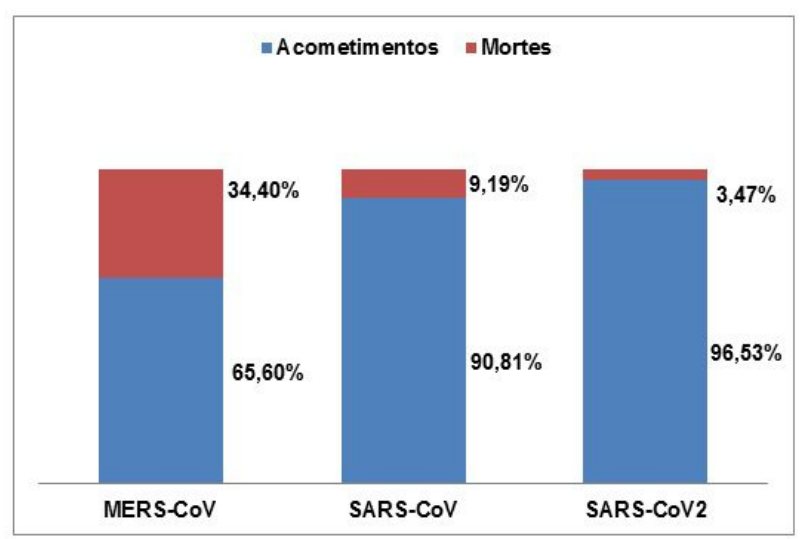

Gráfico 01 - Comparativo entre as Taxas de Acometimento e Mortalidade do SARS-CoV, MERS-CoV e SARS-CoV-2

Fonte-Produzido pelos Autores com Base nos Dados de Rabaan et al. (2020)
O hospedeiro, usualmente entra em contato com o SARS-CoV-2 através de gotículas, aerossóis dispersos no ar ou presentes em superfícies contaminadas, ainda na forma ativa. O COVID-19 apresenta em sua superfície celular projeções em forma de espículas, formadas por trímeros da proteína $S$ (spike protein), em forma de coroa, daí a denominação Coronavírus (CORBETT, et al., 2020; ZHU et al., 2020).

Os domínios S1 e S2 da proteína spike são responsáveis pela adesão do vírus nas superfícies das células do hospedeiro (neurônios, alvéolos, cardiomiócitos, enterócitos, néfrons, e outras). Uma vez aderida, a proteína $S$ reconhece através de seu domínio ligante do receptor (RBD) o receptor ACE2 (enzima conversora de angiotensina 2) (Figura 01). Há, então, a fusão da membrana do SARS-CoV-2 e a membrana celular do hospedeiro, seguindo a interiorização do COVID-19 no citoplasma da célula hospedeira (MAHMOOD, et al., 2020; MCCALLUM., 2020).

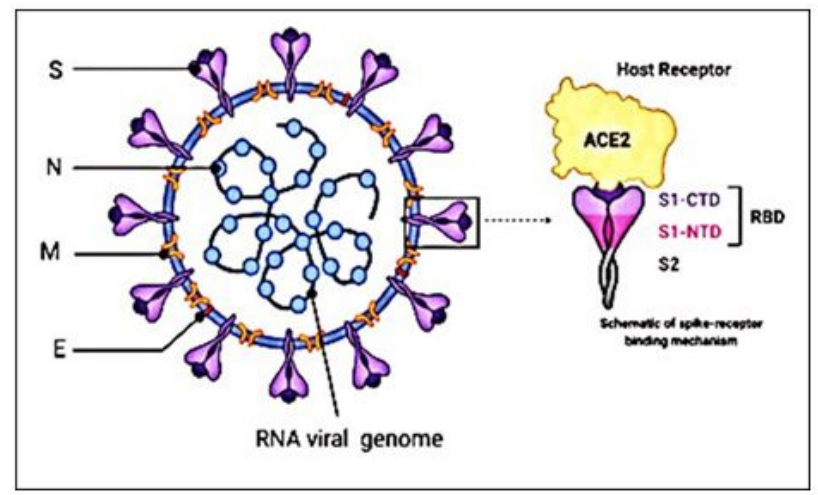

Figura 01 - Estrutura viral SARS-CoV-2 e interação RBD-ACE2 Fonte-MAHMOOD et al. (2020)

RESPOSTAS IMUNOLÓGICAS ADAPTATIVAS NA PROFILAXIA DE VACINA

A resposta imune do tipo Th1 desempenha um papel dominante em uma imunidade adaptativa a infecções virais. As células apresentadoras de antígeno dita a direção das respostas das células T. As células $T$ auxiliares orquestram a resposta adaptativa geral, enquanto as células T citotóxicas são essenciais para matar as células infectadas por vírus. Resposta imune humoral, especialmente a produção de anticorpos neutralizantes, desempenha um papel protetor ao limitar a infecção na fase posterior e evita a reinfecção no futuro (PROMPETCHARA, et al., 2020).

Os epítopos de células $T$ e B foram extensivamente mapeados para as proteínas 
estruturais, S, N, M e proteína para SARS-CoV. A infecção por SARS-CoV induz soroconversão já no quarto dia após o início da doença, e foi encontrado na maioria dos pacientes após quatorze dias. IgG específico de longa duração e anticorpos neutralizantes são relatados até 2 anos após a infecção. Para MERS-CoV a soroconversão é observada na segunda ou terceira semana do início da doença. Em ambas as infecções, a resposta tardia e fraca de anticorpos está associada a resultados graves. No entanto, o perfil de soroconversão sorológica relacionada com o SARS-CoV-2 tem sido ainda pouco descrito na literatura. Em um estudo preliminar, um paciente apresentou pico IgM específico no dia 9 após o início da doença, e a mudança para IgG na segunda semana. Curiosamente, o soro de 5 pacientes confirmados para infecção pelo COVID-19 mostrou alguma reatividade cruzada com SARS-CoV, mas não apresentou reatividade com outros Coronavírus. Além disso, todos os soros de pacientes foram capazes de neutralizar SARS-CoV-2 em um ensaio in vitro, sugerindo uma possível modelagem do humoral de resposta cruzada neutralizante. No entanto, há ainda necessidade de novas investigações focando a titulação de anticorpos específicos correlacionando-se com a gravidade da doença (PROMPETCHARA, et al., 2020).

A resposta das células TCD8+ no SARS-CoV foi mais frequente e com maior magnitude do que as respostas das células T CD4 +. Além disso, as células $T$ específicas do vírus do grupo grave tendem a ser um fenótipo de memória central com uma frequência significativamente maior de células T CD4 + polifuncionais (IFNY, TNF $\alpha$ e IL-2) e Células T CD8 + (IFN $\gamma, T N F \alpha$ ), em comparação com o grupo leve a moderado. Respostas de células $T$ correlacionou-se significativamente com maior titulação de anticorpo neutralizante assim como citocinas Th2 séricas (IL-4, IL-5, IL-10) foram detectadas no grupo fatal (PROMPETCHARA, et al., 2020).

Para o mapeamento de epítopos, a maioria das respostas foi encontrada contra as proteínas estruturais (espícula, envelope, membrana e nucleocapsídeo). Na infecção MERS-CoV, o aumento precoce de células T CD8 + se correlaciona com a gravidade da doença e na fase de convalescença. As respostas de célula TCD 8 +, embora crucial, precisam ser bem controladas para não causar patologia pulmonar. As evidências atuais indicam fortemente que a resposta do tipo Th1 é a chave para o controle bem-sucedido de SARS-CoV e MERSCoV e provavelmente também para o SARS-CoV-2. A maioria dos epítopos identificados para ambos os vírus concentram-se nas proteínas de estrutura viral, desta forma, o mapeamento dos epítopos identificados de SARS-CoV / MERS-CoV com os do SARS-CoV 2 através da sobreposição será fundamental para o desenho esquemático para estudos sobre imunização passiva, usando soro convalescente de pacientes recuperados de SARS ou MERS. Já a identificação dos epítopos de células $T$, vai ajudar na concepção de reatividade cruzada de uma vacina capaz de proteger contra todos os três Coronavírus humanos no futuro. No geral, embora os pacientes que se recuperaram do COVID-19 tenham apresentado diversas características de reconhecimento imunológico eficaz da proteína $\mathrm{S}$, o amplo espectro de atividade neutralizante observado sugere que as vacinas podem exigir estratégias para atingir seletivamente epítopos virais mais potentes (JUNO et al., 2020).

Em referência aos epítopos de células $B$, estudos in silico foram realizados para predispor os epítopos capazes de desenvolver respostas protetoras, e desta forma serem potenciais candidatos para o desenvolvimento de novas vacinas. Um total de 63 epítopos sequenciais de células $B$ na proteína $S$ foram mapeados, dentre eles 4 peptídeos exibiram alta capacidade antigênica e alta exposição superficial.

As pesquisas em desenvolvimento disponíveis na literatura visam induzir respostas imunológicas com anticorpos neutralizantes contra a proteína S viral, impedindo a interação através do receptor da enzima conversora de angiotensina (ACE2). O banco de dados genômicos através de análise de sequência de ácido nucleico dentro do domínio de ligação ao receptor da proteína demonstram similaridade de genoma com SARS. Foi previsto então, que SAR-CoV-2 pode também ter afinidade ao receptor da enzima conversora de angiotensina em células que expressam receptor. Tais estudos realizaram experimentos in vitro que confirmam que o SAR-CoV-2 usou ACE2 para interiorizar a célula alvo. As espécies animais que expressam ACE 2 fundamentam os eventos de transmissão entre indivíduos de mesma espécie e entre espécies diferentes (MAHMOOD et al., 2020).

A glicoproteína $S$ promove adesão do SARSCoV-2 na superfície da célula hospedeira, seguida da interiorização na célula hospedeira. A proteína S é o principal alvo dos anticorpos neutralizantes, sendo foco do design de vacinas. No entanto, sua 
estabilidade e dinâmica conformacional são fatores que dificultam o desenvolvimento de resposta.

Estudo recente relata um projeto de construção correspondente ao trímero do ectodomínio da proteína S de SARS-CoV-2 pré-fusão, covalentemente estabilizado por uma ligação dissulfeto na conformação fechada. Análises conformacionais e de antigenicidade demonstraram que a proteína $\mathrm{S}$ foi preservada estruturalmente no estado fechado. Os autores demonstraram que essa estratégia é aplicável a outros $\beta$-coronavírus, como SARS-CoV e MERS-CoV, e pode se tornar uma ferramenta importante para estudos de biologia estrutural, sorologia, desenho de vacinas e imunologia (KLIMEK et al., 2020). A Figura 02, a seguir apresenta o sequenciamento do genoma do SARSCOV-2.

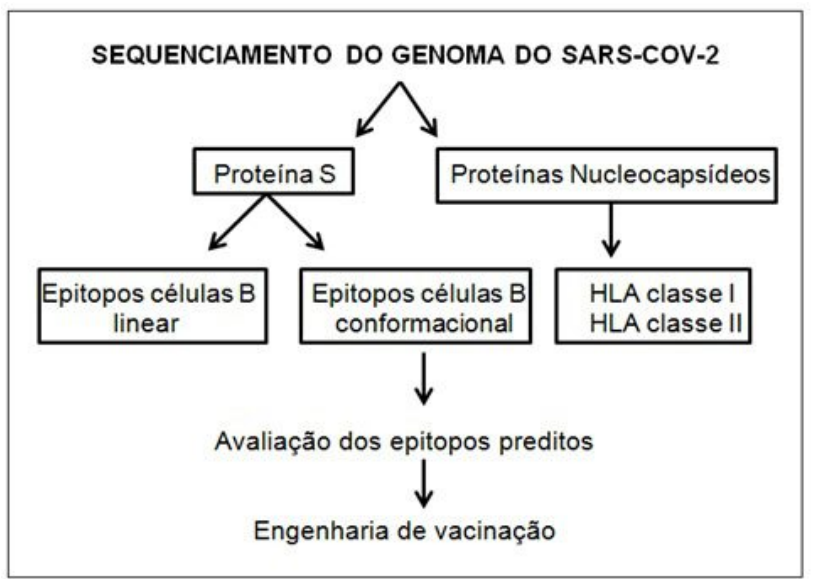

Figura 02-Sequenciamento do Genoma do SARS-COV-2

Fonte-Produzido pelos autores a partir de dados de KLIMEK et al. (2020)

\section{TECNOLOGIAS ENVOLVIDAS NAS PRINCIPAIS CANDIDATAS À VACINA}

O passo inicial para o desenvolvimento de uma estratégia de vacina é a avaliação da importância clínica do agente patológico para uma determinada população. Atualmente o mundo vive uma situação pandêmica com grandes e significativos impactos negativos para a humanidade. Assim, os esforços no desenvolvimento de tecnologias para a produção de vacinas contra o COVID-19, em escala global, tornouse grande prioridade. Têm sido registrados grandes avanços num relativamente curto espaço de tempo. Segundo Vallenta et al. (2016) o desenho da estratégia de um protocolo de vacinação é o seguinte: 1. Descoberta in vitro de antígenos relevante para uma determinada população;

2. Conhecimento estrutural do epítopo envolvido na resposta imunológica robusta;
3. Engenharia do inoculo imunizante;

4. Estudo clínico em animais;

5. Ensaios clínicos de vacinas: com humanos. Este processo envolve princípios éticos rigorosos de consentimento e se utiliza voluntários informados;

6. Análises de segurança de vacinas, imunogenicidade e eficácia.

Para Strategies (1995) (apud ZHU et al., 2020) as fases para o desenvolvimento de vacinas são:

I. Ensaios em pequena escala de pacientes para avaliar se a vacina é segura em humanos e qual resposta imune ela é capaz de induzir.

II. Ensaios em grande escala para avaliar a eficácia da vacina, os efeitos colaterais e as respostas imunes.

Nesta fase também se avalia a eficácia e segurança em populações selecionadas de pacientes imunossuprimidos e idosos. Os objetivos nesta etapa são definir a dose-resposta, tipo de paciente, freqüência de dosagem e numerosas outras características de segurança e eficácia.

III. Amplitude do grupo de estudo, introduzindo em diferentes populações até 10 mil voluntários.

IV. Amplitude do grupo de estudo, superior a 100mil voluntários, seguindo com o licenciamento e introdução no mercado e vigilância póscomercialização.

A avaliação clínica científica do processo de produção de vacinas pré-licenciamento deve preencher critérios científicos rigorosos nas fases I-III. Sua eficácia é determinada pela porcentagem de redução na incidência da doença (vacinado versus não vacinado), também é avaliado seu tempo de validade, complexidade, custo e limitações da validade.

$\mathrm{Na}$ fase pós-licenciamento (fase IV) é avaliada a capacidade protetora de uma vacina em relação à doença alvo em populações. Seria uma visão do "mundo real" de como uma vacina (que já tenha sido provada ter alta eficácia) reduz a doença em uma população. Avalia-se o equilíbrio líquido dos benefícios e os efeitos adversos num determinado programa de vacinação (VALENTA et al., 2016).

\section{CENÁRIO GLOBAL DE DESENVOLVIMENTO DA VACINA PARA COVID-19}

O cenário global na produção de vacinas inclui 150 vacinas candidatas cadastradas na OMS, das quais 78 são confirmadas como ativas onde 73 estão atualmente em estágios exploratórios ou préclínicos. As mais avançadas recentemente iniciaram as fases clínicas I e II. Uma marcante característica do 
cenário de desenvolvimento de vacinas contra o COVID-19 é a variedade de plataformas de tecnologias sendo avaliadas, incluindo ácido nucleico (DNA e RNA), partículas virais semelhantes, peptídeos, vetores virais (replicante e não replicante), proteínas recombinantes, vírus vivos atenuados e vírus inativados. Muitas dessas plataformas são inovações científicas globais. É, no entanto, concebível que algumas plataformas de vacinas sejam mais adequadas para subtipos populacionais específicos, como por exemplo: crianças, grávidas, idosos, mulheres ou pacientes imunocomprometidos (SOCIEDADE BRASILEIRA DE IMUNOLOGIA, 2020).

As novas plataformas baseadas em DNA ou mRNA oferecem grande flexibilidade em termos de antígenos, manipulação e maior velocidade. A empresa americana Moderna, começou os testes clínicos de sua vacina baseada em mRNA mRNA1273 apenas 2 meses após a identificação da sequência. No entanto, vacinas baseadas em vetores virais oferecem um alto nível de expressão de proteína, longo prazo de estabilidade e induzem forte resposta imunológica. As vacinas baseadas em proteínas recombinantes, por sua vez, já estão mais estabilizadas no universo científico de produção de vacinas. Desta forma, as vacinas baseadas em proteínas recombinantes beneficiam-se em larga escala no quesito capacidade de produção. Para algumas plataformas, os adjuvantes podem aumentar a imunogenicidade e diminuir doses viáveis, permitindo assim a vacinação em maior escala, sem comprometer a proteção. Até agora, os adjuvantes cogitados em uso nas pesquisas que visam à elaboração da vacina contra o COVID-19 são: AS03, MF59 e CpG 1018 (THANH, et al., 2020).

De acordo com o atual avanço tecnológico, a vacina de mRNA, outra vacina à base de ácido nucleico, tem sido considerada como tecnologia de vacinação disruptiva. Projetos recentes de vacinas de mRNA melhoraram a estabilidade e eficiência de tradução de proteínas, portanto, poderia induzir respostas imunes robustas. A vacina mRNA - 1273 que codifica uma forma estabilizada de pré-fusão da proteína spike (S) do SARS-CoV-2, tem mostrado alta eficácia na boa tolerância humana de produção de anticorpos duráveis contra o antígeno $S$ do SARSCoV-2 (CORBETT, et al., 2020; THANH, et al., 2020).

Os ensaios clínicos de fase I e II desta vacina envolveu cerca de 1600 participantes norteamericanos, sob rigorosa supervisão de autoridades científicas, tanto dos EUA quanto da Europa e
Austrália. Os endpoints primário e secundário da vacina mRNA - 1273 nas fases I e ll foram a prevenção da doença sintomática pelo COVID-19 e num segundo momento, tanto a prevenção da doença sintomática quanto a prevenção de doença grave pelo SARS-CoV-2, definida como necessidade de hospitalização. Resultados satisfatórios com relação aos endpoints mencionados foram alcançados com a dose de $100 \mu \mathrm{g}$ da vacina nos candidatos. Essa dose que se mostrou capaz de maximizar a resposta imune contra o COVID-19, além de apresentar muito boa tolerância aos poucos efeitos adversos. Satisfatoriamente superado os ensaios clínicos de fase l e II, encontra-se em curso desde julho de 2020 o ensaio clinico de fase III, randomizado 1:1 controlado por placebo desta vacina mRNA-1273. Envolvendo cerca de 30.000 participantes nos EUA, com aprovação do Food and Drug Administration (FDA) (CORBETT, et al., 2020).

Sistema de entrega, como nanopartículas de lipídios, O LNP também foi bem otimizado. Dentro de dois meses após o surto SAR-CoV-2, pelo menos 37 empresas biofarmacêuticas ou setores acadêmicos estão em corrida para desenvolver a vacina profilática usando várias plataformas, incluindo mRNA, DNA, vetor adenoviral e proteína recombinante THANH, et al., 2020).

Para tornar possível a vacina SAR-CoV-2, a coleta de informações importantes para o seu desenvolvimento e avaliação devem ser bem definidos. Isso inclui encontrar o antígeno alvo, rota de imunização, proteção imune correlacionada, modelos animais, escalabilidade, produção, previsão de surto e população alvo. A colaboração internacional, bem como a transferência de tecnologia entre especialistas também ajudarão o desenvolvimento de vacinas rapidamente. A fim de acelerar a vacina disponível durante surto em andamento, estudos pré-clínicos da vacina SAR-CoV2 podem precisar ser realizados em paralelo com ensaios laboratoriais. No entanto, antes de entrar nos testes clínicos as agências reguladoras devem avaliar o processo de produção e informações préclínica para garantir a segurança dos voluntários.

Observando as semelhanças e diferenças entre SARS-CoV-2 e o surto anterior de SARS e MERS, uma semelhança impressionante emerge com algumas características exclusivas próprias. Como o COVID-19 causa problemas graves de saúde pública em todo mundo, investigação sobre as características do SARS-CoV-2, interação com as respostas imunes do hospedeiro pode ajudar a fornecer uma imagem 
mais clara de como o patógeno causa doenças em alguns indivíduos, enquanto a maioria das pessoas infectadas mostra apenas leve ou nenhuma sintomas em tudo. Além disso, os estudos correlatos imunológicos de proteção e a memória imunológica de longo prazo de indivíduos convalescentes podem ajudar no desenho de medidas profiláticas e terapêuticas para surtos futuros de Coronavírus semelhante (THANH, et al., 2020).

Os trabalhos da BioNTech e Pfizer apresentaram os resultados dos testes clínicos de fase I e II da vacina para COVID-19 e demonstraram que foi possível induzir uma resposta imune eficaz e não gerou efeitos colaterais graves nos 45 voluntários adultos. A vacina, BNT162b1, é constituída de mRNA modificado que codifica o RDB da glicoproteina spike trimerizada de SARS-CoV-2, formulada em nanopartículas lipídicas. Os níveis de anticorpos neutralizantes dos participantes foram de 1,9 a 4,6 vezes maiores do que os de pacientes em recuperação da COVID-19 (MULLIGAN et al., 2020).

A farmacêutica NOVAVAX apresentou os resultados dos testes da fase I para sua versão da vacina para COVID-19, o ensaio foi randomizado, controlado por placebo com e sem adjuvante Matrix$\mathrm{M}^{\mathrm{TM}}$ em adultos saudáveis com idade entre 18 e 59 anos. A vacina adotou a tecnologia recombinante, nomeada NVX-CoV2373, e no geral, foi bem tolerada e capaz de desenvolver uma resposta robusta humoral superior à encontrada em soro convalescente humano (NOVAVAX, 2020).

Das vacinas candidatas ativas confirmadas, 56 estão sendo desenvolvidas por empresas privadas, uma série de grandes multinacionais (Janssen, Sanofi, Pfizer e GlaxoSmithKline) correspondendo a $78 \%$, e 22 projetos sendo liderados por centros acadêmicos públicos e outras organizações sem fins lucrativos representando $28 \%$ dos estudos. Embora tenham se comprometido no desenvolvimento da vacina contra o COVID-19, muitos dos principais desenvolvedores são pequenos e inexperientes na fabricação de vacinas em grande escala. Neste cenário é importante garantir a validade científica da fabricação e capacidade de fornecimento das vacinas e atender à demanda. Os principais ensaios clínicos da produção de uma vacina contra o COVID-19 em finalização da fase III ocorrem na América do Norte, com 36 (46\%), além de 14 (18\%) na China, 14 (18\%) na Ásia (excluindo a China) e Austrália, e 14 (18\%) na Europa (THANH, et al., 2020).

A Tabela 01, a seguir, apresenta o resumo das principais candidatas à produção de vacina e as respectivas fases de estudos clínicos.

Tabela 01 - Cenário Global das Principais Prováveis Vacinas

Fonte - Produzido pelos Autores com Dados da Pesquisa

\begin{tabular}{|c|c|c|c|}
\hline Organização & País & Plataforma & Fase \\
\hline Moderna & EUA & Vacina Genética & III \\
\hline BioNTech/Pfizer & $\begin{array}{l}\text { Alemanha } \\
\text { /EUA }\end{array}$ & Vacina Genética & III \\
\hline $\begin{array}{l}\text { Academia de Ciências Militares Walvax } \\
\text { Biotech }\end{array}$ & China & Vacina Genética & III \\
\hline $\begin{array}{l}\text { Universidade deOsaka/AnGes/Takara } \\
\text { Bio }\end{array}$ & Japão & Vacina Genética & II \\
\hline Oxford / Astrazeneca & $\begin{array}{l}\text { Reino } \\
\text { Unido }\end{array}$ & Vetor Viral & III \\
\hline CanSino Biological & China & Vetor Viral & II \\
\hline Janssen Pharmaceutical & EUA & Vetor Viral & II \\
\hline Instituto Gamaleya & Rússia & Vetor Viral & II \\
\hline $\begin{array}{l}\text { Anhui Zhifei Longcom } \\
\text { Biopharmaceutical / Instituto de } \\
\text { Microbiologia da Academia Chinesa de } \\
\text { Ciências }\end{array}$ & China & Base de Proteína & II \\
\hline Novavax & EUA & Base de Proteína & II \\
\hline Sinovac & China & Vírus Inativado & III \\
\hline $\begin{array}{l}\text { Instituto de Produtos Biológicos de } \\
\text { Wuhan/Sinopharm }\end{array}$ & China & Vírus Inativado & III \\
\hline $\begin{array}{l}\text { Instituto de Produtos Biológicos de } \\
\text { Pequim/Sinopharm }\end{array}$ & China & Vírus Inativado & III \\
\hline
\end{tabular}

\section{CENÁRIO BRASILEIRO DE DESENVOLVIMENTO DA VACINA PARA COVID-19}

Atualmente no Brasil, quatro estudos de vacinas contra o novo Coronavírus foram autorizados pela Agência Nacional de Vigilância Sanitária (ANVISA). No dia 2 de junho de 2020 a agência autorizou o ensaio clínico das vacinas desenvolvidas pelas empresas AstraZeneca e pela Universidade de Oxford, do Reino Unido; no dia 3 de julho autorizou a vacina que está sendo desenvolvida pela Sinovac Biotech da China, em parceria com o Instituto Butantã; e no dia 21 de julho as vacinas da BioNTech da Alemanha e Wyeth/Pfizer dos EUA (AGÊNCIA BRASIL, 2020).

Recentemente a ANVISA autorizou a unidade farmacêutica da Johnson \& Johnson - Jansen-Cilag para realização de testes clínicos no Brasil. Para tanto, os estudos científicos possuem a perspectiva de inclusão de até 60 mil voluntários, incluindo $7 \mathrm{mil}$ brasileiros, residentes dos estados de Rio de Janeiro, Paraná, São Paulo, Rio Grande do Sul, Minas Gerais, Bahia e Rio Grande do Norte. Os estudos da 
supracitada farmacêutica também foram iniciados em julho de 2020 nos EUA e na Bélgica. A potencial vacina da Jansen-Cilag, denominada Ad26.COV2.S, é por engenharia de um vetor recombinante, não replicante, de adenovírus tipo 26 (Ad26), codificante para a proteína S (Spike) do vírus Sars-CoV-2. O ensaio clínico em desenvolvimento apresenta um estudo de fase III, randomizado, duplo cego, controlado por placebo, para avaliar a segurança e eficácia de Ad26.COV2.S. Os testes de prevenção de Covid-19 serão realizados em adultos com 18 anos ou mais, já o recrutamento de voluntários é de responsabilidade dos centros que conduzem a pesquisa. Para tanto, cada participante receberá uma dose única da vacina ou placebo (AGÊNCIA BRASIL, 2020).

A Universidade de São Paulo (USP) está desenvolvendo uma versão brasileira da vacina para COVID -19 com a perspectiva de estar disponível em 2021. A vacina será desenvolvida em spray, sendo por tanto mais fácil de ser aplicada e com custo menor. A promissora vacina pode garantir a independência do Brasil quanto à fabricação e produção e de se tornar independente de empresas estrangeiras. Os últimos os resultados apresentados da fórmula desenvolvida pela USP em parceria com o Instituto do Coração (INCOR) foram positivos. No entanto a vacina brasileira ainda está na fase de testagem pré-clínica (AGÊNCIA BRASIL, 2020).

\section{CONSIDERAÇÕES FINAIS}

Uma vacina eficaz contra o COVID-19 move atualmente a comunidade científica frente a uma pandemia que desde dezembro de 2019 acomete o mundo. No momento, existem cerca de 150 vacinas sendo desenvolvidas, em plataformas tenológicas específicas, e em distintas fases de ensaios clínicos: testando a eficácia clínica imunológica, produção de potentes e sustentáveis anticorpos contra as células humanas infectadas pelo COVID-19. Alcançando-se esta meta, a vacina seria produzida e ofertada em escala global. Contudo, sabe-se que a produção de vacinas demanda variável intervalo de tempo. Distintas fases de ensaios pré-clínicos, rigorosamente controlados pelas determinações, diretrizes vigentes, universalmente validadas com relação à ética e segurança da pesquisa científica. As quais objetivam investigar a real eficácia clínica imunológica, possíveis efeitos adversos e boa tolerância humana destas vacinas.

No que se refere às tecnologias envolvidas na produção de uma vacina contra o SARS-CoV-2, trata-se de um grande desafio científico de real complexidade. Felizmente tem havido notável dinâmica no progresso global no que diz respeito às pesquisas e processos de desenvolvimento destas tecnologias para produção de uma vacina eficaz e sustentável de anticorpos humanos contra o SARSCoV-2. Um exemplo destacado neste cenário global de desenvolvimento de tecnologias para produção de vacinas contra o COVID-19 é a tecnologia utilizada na produção da vacina mRNA - 1273 que codifica uma forma estabilizada de pré-fusão da proteína spike (S) do SARS-CoV-2, e que tem mostrado alta eficácia e boa tolerância humana de produção de anticorpos duráveis contra o antígeno S do SARS-CoV-2. Em progresso de evolução da fase III de ensaios clínicos.

Numa perspectiva global estes resultados clínicos científicos bem-sucedidos e bastante promissores, seguem nutrindo grandes esperanças para o bom controle de infecção, altas taxas de mortalidade e definitiva contingência de propagação global do SARS-CoV-2. Por outro lado, sinalizam demandas de revisões globais dos paradigmas, parâmetros, fundamentos éticos e bioéticas científicas. A questão é: Estaria paralelamente em curso uma nova reconstrução sistematizada do paradigma científico global? E assim sendo, seria algo diferente a dinâmica realidade inerente à essência da natureza da ciência?

Embora exista um arcabouço científico global muito significativo para que a inovação tecnológica aconteça no que diz respeito à produção de vacinas, neste momento específico contra o Coronavírus é necessário existir uma forte política cultural específica que contemple e norteie todas as diretrizes éticas relacionadas com estas atividades. Pois, se tratam de procedimentos, processos, parâmetros específicos, com peculiaridades diferentes daqueles envolvidos propriamente na pesquisa científica. Esses aspectos inerentes às vigentes inovações tecnológicas relacionadas com a produção global de vacinas contra o COVID-19 parecem que ainda não estão bem esclarecidos, se encontram de forma sedimentada no meio acadêmico, nas instituições de pesquisas, e nas indústrias transnacionais. A ponto de, demonstrarem através da mídia, sinais de desequilíbrios e conflitos de diferentes naturezas, que chegam a por em questão a secular certeza da força dos ideais éticos científicos. 


\section{REFERÊNCIAS}

AGÊNCIA BRASIL. Covid-19: ANVISA autoriza testes para nova vacina da Johnson \& Johnson. Disponível em: https//agenciabrasil.ebc.com.br/saude/noticia/2020-08/covid-19-anvisa-autoriza-testes-para-nova-vacina-da-johnsonjohnson. 18 de agosto de 2020. Acesso em: 31 de agosto de 2020.

CALLAWAY, Ewen; LEDFORD, Heidi; MALLAPATY, Smriti. Six months of coronavirus: the mysteries scientists are still racing to solve. Nature. 2020; v. 583, n. 7815, p. 178-179. DOI: 10.1038/d41586-020-01989-z.

CORBETT, Kizzmekia S. et al. Evaluation of the mRNA-1273 Vaccine against SARS-CoV-2 in Nonhuman Primates. New England Journal of Medicine. 2020. DOI: 10.1056/NEJMoa2024671.

JUNO, Jennifer A. et al. Humoral and circulating follicular helper T cell responses in recovered patients with COVID-19. Nature medicine. 2020; p. 1-7. DOI: https://doi.org/10.1038/s41591-020-0995-0.

KLIMEK, L; PFAAR, O; WORM, M et al. Allergen immunotherapy in the current COVID-19 pandemic: A position paper of AeDA, ARIA, EAACI, DGAKI and GPA: Position paper of the German ARIA GroupA in cooperation with the Austrian ARIA GroupB, the Swiss ARIA GroupC, German Society for Applied Allergology (AEDA)D, German Society for Allergology and Clinical Immunology (DGAKI)E, Society for Pediatric Allergology (GPA)F in cooperation with AG Clinical Immunology, Allergology and Environmental Medicine of the DGHNO-KHCG and the European Academy of Allergy and Clinical Immunology (EAACI)H. Allergol Select. 2020; v. 4, p. 44-52. DOI:10.5414/ALX02147.

MAHMOOD, Zafar et al. Investigating Virological, Immunological, and Pathological Avenues to Identify Potential Targets for Developing COVID-19 Treatment and Prevention Strategies. Vaccines. 2020; v. 8, n. 3, p. 443.

MCCALLUM, Matthew et al. Structure-guided covalent stabilization of coronavirus spike glycoprotein trimers in the closed conformation. Nature Structural \& Molecular Biology. 2020; p. 1-8. DOI: https://doi.org/10.1038/s41594-020-0483-8.

MULLIGAN, M.J.; LYKE, K.E.; KITCHIN, N. et al. Phase 1/2 study of COVID-19 RNA vaccine BNT162b1 in adults. Nature. 2020; p 1-8. DOI: doi.org/10.1038/s41586-020-2639-4. 2020.

NOVAVAX. Announces Positive Phase 1 Data for its COVID-19 Vaccine Candidate. Disponível em:

http://ir.novavax.com/news-releases/news-release-details/novavax-announces-positive-phase-1-data-its-covid-19-vaccine. 4 de Agosto de 2020. Acesso em: 22 de Agosto de 2020.

PROMPETCHARA, Eakachai; KETLOY, Chutitorn; PALAGA, Tanapat. Immune responses in COVID-19 and potential vaccines: Lessons learned from SARS and MERS epidemic. Asian Pac J Allergy Immunol. 2020; v. 38, n. 1, p. 1-9.

RABAAN, AA; AL-AHMED, SH; HAQUE S, et al. SARS-CoV-2, SARS-CoV, and MERS-CoV: a comparative overview. Infez Med. 2020; v. 28, n. 2, p. 174-184.

SOCIEDADE BRASILEIRA DE IMUNOLOGIA (SBI). Nota técnica sobre o desenvolvimento e eficácia de vacinas para a COVID19. 2020. Disponível em: https://sbi.org.br/2020/08/14/nota-tecnica-da-sociedade-brasileira-de-imunologia-sbi-sobre-odesenvolvimento-e-eficacia-de-vacinas-para-a-covid-19/. Acesso em: 20 de agosto de 2020.

STRATEGIES, I. 2 . Vaccine Development Development of Vaccines and Immunization Strategies. 1995.

THANH, Le T; ANDREADAKIS, Z; KUMAR A, et al. The COVID-19 vaccine development landscape. Nat Rev Drug Discov. 2020; v. 19, n. 5, p. 305-306. doi:10.1038/d41573-020-00073-5.

VALENTA, R. et al. Vaccine development for allergen-specific immunotherapy based on recombinant allergens and synthetic allergen peptides: Lessons from the past and novel mechanisms of action for the future. Journal of Allergy and Clinical Immunology, v. 137, n. 2, p. 351-357, 2016.

ZHOU, H; CHEN, X; HU, T; et al. A Novel Bat Coronavirus Closely Related to SARS-CoV-2 Contains Natural Insertions at the S1/S2 Cleavage Site of the Spike Protein. Current Biology. 2020; 30, 2196-2203.

ZHU, N; ZHANG, D; WANG, W; et al. A Novel Coronavirus from Patients with Pneumonia in China, 2019. N Engl J Med. 2020; v. 382, n. 8, p 727-733. DOI: 10.1056/NEJMoa2001017. 


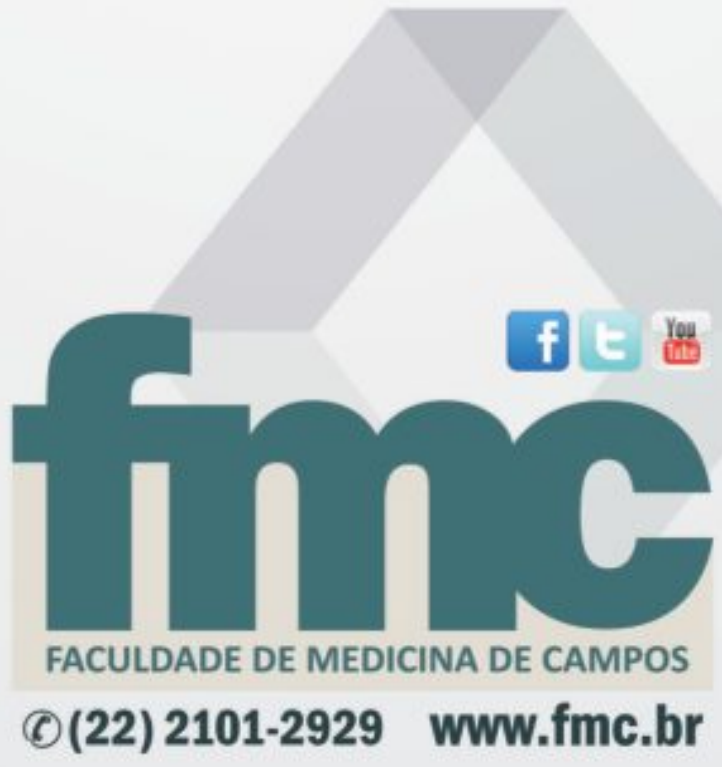

